Portland State University

PDXScholar

1982

\title{
Speech intelligibility as a function of the propositionality of background noise
}

Gail Swanstrom

Portland State University

Follow this and additional works at: https://pdxscholar.library.pdx.edu/open_access_etds

Part of the Cognition and Perception Commons, and the Speech and Hearing Science Commons Let us know how access to this document benefits you.

\section{Recommended Citation}

Swanstrom, Gail, "Speech intelligibility as a function of the propositionality of background noise" (1982). Dissertations and Theses. Paper 3242.

https://doi.org/10.15760/etd.3234

This Thesis is brought to you for free and open access. It has been accepted for inclusion in Dissertations and Theses by an authorized administrator of PDXScholar. Please contact us if we can make this document more accessible: pdxscholar@pdx.edu. 
AN ABSTRACT OF THE THESIS OF Gail Swanstrom for the Master of Science in Speech Communication presented May 20, 1982.

Title: Speech Intelligibility as a Function of the Propositionality of Background Noise.

APPROVED BY MEMBERS OF THE THESIS COMMITTEE:
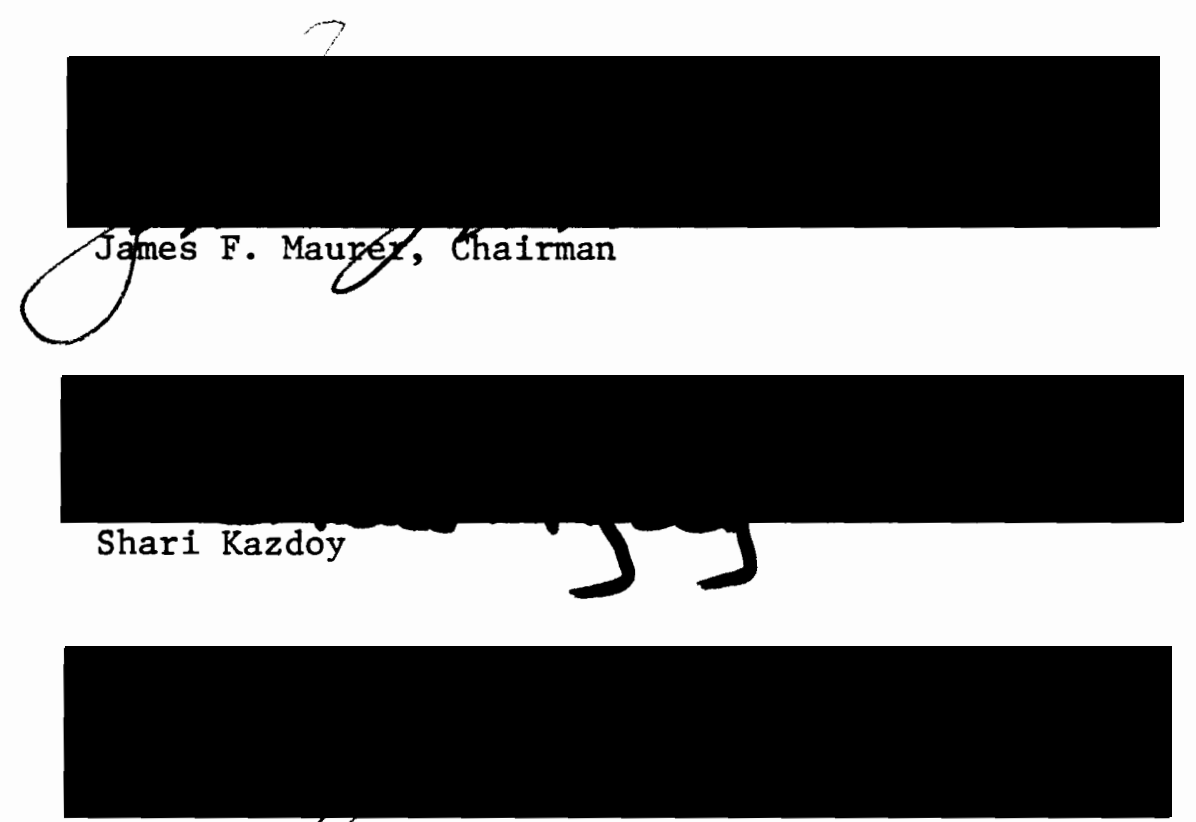

Keith Larsgn

The purpose of this investigation was to measure the ability of young normal hearing listeners to perceive speech in the presence of a background noise which varies in the relative intensity of its semantic content. The Speech Perception in Noise test was mixed with a two-component competing noise complex in which the narrativeto-speech noise ratio varied in $2 \mathrm{~dB}$ increments from $-2 \mathrm{~dB} \mathrm{Na} / \mathrm{SpN}$ 
to $+8 \mathrm{~dB} \mathrm{Na} / \mathrm{SpN}$. These stimuli were presented at an overall $+8 \mathrm{~dB}$ signal-to-noise ratio to thirty young normal hearing adults through the soundfield system. The differences between the mean error scores and standard deviations for the low predictability sentences were found to be statistically significant at all $\mathrm{Na} / \mathrm{SpN}$ ratios. No main effect was observed for the $\mathrm{Na} / \mathrm{SpN}$ ratios on the high predictability sentences. Significant differences were also observed between the mean error scores and standard deviations of $\mathrm{HP}$ and $\mathrm{LP}$ pairs at each $\mathrm{Na} / \mathrm{SpN}$ ratio. These data further revealed a systematic increase in LP mean error scores and standard deviations as a result of linear increases in the $\mathrm{Na} / \mathrm{SpN}$ ratio. These results suggest that semantically loaded competing noise significantly influences the perception of primary messages as a direct function of the competition ratio. 


\section{SPEECH INTELLIGIBILITY AS A FUNCTION OF THE PROPOSITIONALITY OF BACKGROUND NOISE}

by

Gail Swanstrom

A thesis submitted in partial fulfillment of the requirements for the degree of

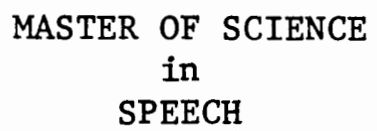

with emphasis in Speech Pathology

and Audiology

Portland State University 
TO THE OFFICE OF GRADUATE STUDIES AND RESEARCH:

The members of the Committee approve the thesis of Gail

Swanstrom presented on May 20, 1982.

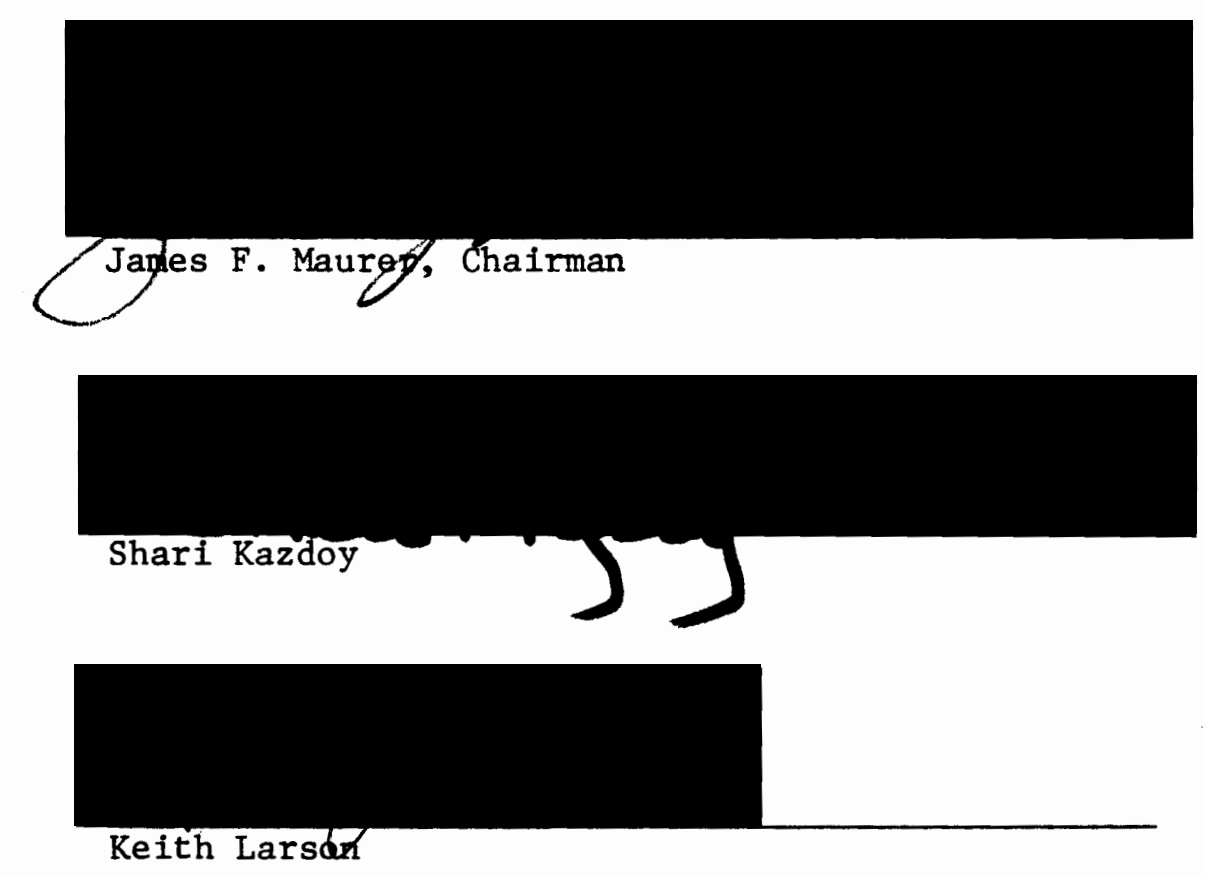

APPROVED:

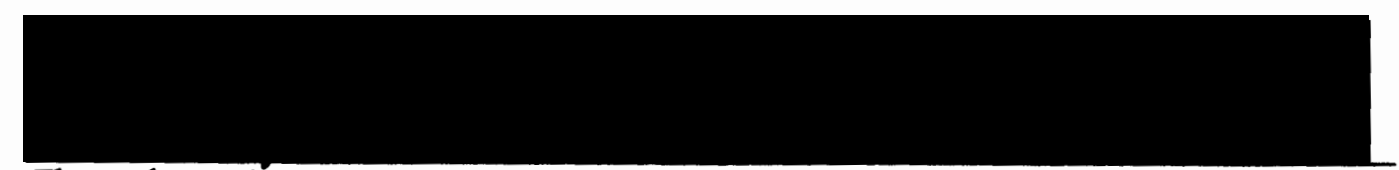

Theordore G. Grove, Head, Department of Speech Communication

Stanley E. Rauch, Dean of Graduate Studies and Research 
TABLE OF CONTENTS

PAGE

LIST OF TABLES .................... . . v LIST OF FIGURES . . . . . . . . . . . . . vi vi

CHAPTER

I INTRODUCTION .................. 1

II REVIEW OF THE LITERATURE ........... 3

Speech Discrimination Testing. . . . . 3

Speech-in-Noise Testing. . . . . . . . 5

Speech Perception in Noise Test....... 21

Summary. . . . . . . . . . 25

PURPOSE. . . . . . . . . . . . . 26

Rationale. . . . . . . . . 26

III METHODS. . . . . . . . . . . 29

Subjects ............ . . 29

Procedure. . . . . . . . . . 29

Instrumentation. . . . . . . . 31

Calibration. .......... 32

IV RESULTS. . . . . . . . . . . . . 33

$\mathrm{V}$ DISCUSSION .................... 41

Conclusion . . . . . . . . . . 44

Implications for Future Research . . . . 45 
CHAPTER

PAGE

REFERENCES 


\section{LIST OF TABLES}

I Mean percent correct and standard deviations for scores on CID $W-22$ Auditory Test in quiet and in noise for normal hearing subjects. . . . . . . . . . . . . . 9

II Mean percent correct and ranges for scores on CID W-22 Auditory Test related to kinds and levels of noise for normal hearing subjects. . . . . . . . . . . . 10

III Mean percent correct, median percent correct, range, and standard deviation for scores on CID W-22 Auditory Test at $0 \mathrm{~dB} \mathrm{~S} / \mathrm{N}$ for normal hearing subjects. . . . . . 22

IV Mean errors and standard deviations for scores on $\mathrm{HP}$ and LP SPIN sentences at $\mathrm{Na} / \mathrm{SpN}$ ratio for experimental group. . . . . . . 36

$V$ Mean error pairs and $t$ values for differences at $\mathrm{Na} / \mathrm{SpN}$ for experimental group. . . . 40 


\section{LIST OF FIGURES}

1. Comparison of mean percent correct for synthetic sentences in forward (CMF) and backward (CMB) competing message for normal hearing subjects. . . . . . . .

2. Mean percent correct for scores on NU Test 2 as a function of signal-to-noise ratio for normal hearing, conductive, sensorineural, and presbycusic subjects . . . . . . . 14

3. Mean percent correct for CID $W-22$ Auditory Test as a function of signal-to-noise ratio for subjects with normal hearing, high frequency losses and flat losses. . .

4. Ranges for CID $\mathrm{W}-22$ Auditory Test as a function of signal-to-noise ratio for subjects with normal hearing, high frequency losses and flat losses............... 16

5. Mean percent correct for scores on CID $\mathrm{W}-22$ Auditory Test as a function of signal-tonoise ratio for normal hearing and sensorineural subjects . . . . . . . .

6. Speech intelligibility gain as a function of 
signa1-to-noise ratio for normal hearing subjects. . . . . . . . . 20

7. Mean percent correct for scores on HP and LP SPIN Test as a function of signa1-to-noise ratio for young and older normal hearing subjects. . . . . . . . . . 24

8. Mean percent correct for scores on HP and LP $\mathrm{SPIN}$ Test as a function of $\mathrm{Na} / \mathrm{SpN}$ ratio for experimental group. . . . . . . . 34

9. Mean errors and standard deviations on HP and LP SPIN Test as a function of $\mathrm{Na} / \mathrm{SpN}$ for experimental group. . . . . . . . 38 
CHAPTER I

\section{INTRODUCTION}

The ability to hear two sounds at the same time is perhaps the most useful property of the human auditory system. It is this ability which enables a listener to selectively respond to certain acoustic signals while completely ignoring others, to perceive a spoken message amidst a cacaphony of daily environmental noises. Unfortunately, this ability is not perfect and messages are frequently lost or distorted due to the interference of another sound.

In ordinary conversation, most listeners probably fail to hear correctly and completely many words, but do not realize this because the internal redundancy of the words and contextual clues provide enough information to make the conversation understandable. However, the addition of other distorting sources to this noise interference (e.g., hearing impairment, contextual confusion) may cause a complete breakdown of intelligibility. By measuring speech discrimination ability as a function of these interference factors, the audiologist gains insight into a listener's ability to cope with the everyday dynamics of oral communication. Armed with this information as part of a complete diagnostic battery, the audiologist can begin to implement a rehabilitative program 
to help the impaired listener better manage adverse communication situations. Accordingly, this study will attempt to measure the ability of young normal hearing listeners to percelve speech in the presence of a background noise which varies in the relative intensity of its semantic content. 


\section{CHAPTER II}

\section{REVIEW OF THE LITERATURE}

\section{Speech Discrimination Testing}

Speech discrimination testing has both diagnostic and prognostic value as part of the basic diagnostic battery of audiologic tests. By measuring hearing ability in situations similiar to everyday auditory experiences, speech tests attempt to assess the degree of difficulty a person will have understanding continuous discourse (Silverman, 1950; Hirsh, Davis, Silverman, Reynolds, Eldert, and Benson, 1952). Speech discrimination testing also assists in the differentiation between normal hearing individuals and those with hearing impairments as well as in the diagnosis of ear disease (Keith and Talis, 1970; Thornton and Raffin, 1978). In addition, the evaluation of hearing aid performance is frequently based on comparisons between speech discrimination scores (Keith and Talis, 1972).

To fulfill these objectives, the ideal clinical speech discrimination test is one which is sensitive to any deviations from normal speech discrimination ability (Lovrinic, Burgi and Curry, 1968). Several different tests have been developed over the years in attempts to quantify these deviations. Monosyllabic word lists have been widely used, partially due to the ease with which their controlled composition allows for phonetic comparison 
to normal conversational speech. These lists include words of high frequency usage, minimizing the effects of individual vocabulary, and are easy to administer and score (Egan, 1948). Monosyllabic 1ists, however, may not adequately represent conversational speech insofar as they do not include such cues as word predictability, accent, stress, voice quality, duration, and intonation provided in normal speech (Duffy and Giolas, 1974). Continuous discourse has been suggested as the most logical speech message to use in intelligibility testing (Falconer, 1948; Hirsh, 1952). According1y, materials utilizing sentences as the carrier in speech discrimination testing have been developed to upgrade the evaluation of speech intelligibility ability. Sentences and longer linguistic units include the prosodic features represented in conversational speech and, therefore, may provide a more realistic asessment of speech discrimination ability than monosyllabic words (Lehiste and Peterson, 1959).

The most recent advancement in speech intelligibility testing has been the administration of speech materials, either monosyllabic words or sentences, in the presence of background noise. The masking of speech by noise provides the most realistic acoustic environment in which an individual must try to understand speech (Kryter, Williams and Green, 1962). By replicating everyday listening situations, testing speech against a background of noise yields intelligibility scores which are a direct measure of how well a listener is able to participate in a discussion (P1omp and Mimpen, 1979). 
Speech-in-Noise Testing

The deleterious effect of various noises on the intelligibility of speech was first summarized by Miller (1947). Miller investigated the effects of tones, music, noise (FM and white), and voices at several signal-to-noise ratios and concluded that

the greatest interference with vocal communication is produced by an uninterrupted noise which provides a relatively constant speech-to-noise ratio over the entire range of frequencies involved in human speech. Unfortunately, most of the noises we compete with fill this general prescription.

In the intital study comparing the masking of speech in form of continuous discourse by white noise, Hawkins and Stevens (1950) reported that the threshold of speech intelligibility was elevated by masking noise similiar to the thresholds for pure tones. Their data revealed that for noise levels below $10 \mathrm{dBSL}$, the normal thresholds for speech intelligibility were unaffected, but at higher levels of noise the thresholds for speech were raised virtually linearly.

Suggesting that this masking phenomenon did not entirely explain degraded speech intelligibility performance, Harris (1960) investigated the effects of multiple cueing on sentence intelligibility. By systematically introducing five sources of distortion (nasality, increased rate, speaking while eating, reverberation, and interruptions), Harris found that the combination of two distortions could remove up to one-half of the available speech cues, reducing intelligibility to approximately $50 \%$. He theorized that adding a second distortion (e.g., sensorineural hearing loss) to speech already distorted by noise would result in markedly reducing speech 
discrimination ability.

Plomp and Mimpen (1979) also studied the effects of several variables on the intelligibility of speech. Speech reception thresholds using sentence stimuli were determined for subjects at various signal-to-noise ratios and these data were analyzed for factor interaction of sex, age, noise level, subject, and ear. Plomp and Mimpen concluded that the signal-to-noise ratio was the most important source of variance in speech reception threshold tasks, suggesting that ambient noise was the most significant limiting factor in speech intelligibility.

The diagnostic significance of testing speech discrimination ability in the presence of noise was first documented by Simonton and Hedgecock in 1953. Using the Rush-Hughes PAL PB-50 test mixed with white noise at signal-to-noise ratios adjusted for comfort by each subject, the experimenters found no differences in speech discrimination scores obtained in noise between subjects with normal hearing and those with conductive hearing losses. Subjects with sensorineural hearing impairments, however, demonstrated significantly decreased discrimination scores when tested in the presence of noise. Wide individual variations in speech discrimination scores were also noted in the "perceptive deafness" (sensorineural) group, whereas scores in the normal and conductive groups did not vary. These results suggested a significant difference existed in the discrimination ability in noise between subjects with conductive and subjects with sensorineural hearing impairments, but no further conclusions could be drawn due to the limited scope of 
the study.

Palva (1955) found results similiar to those of Simonton and Hedgecock. Presenting Finnish word 1ists in quiet and in wide-band noise at a signal-to-noise ratio of +10 under headphone conditions, he demonstrated that the speech discrimination scores remained unchanged in subjects with normal hearing and conductive hearing losses. Discrimination scores in noise were most clearly lowered for those subjects termed "perceptive" hearing impaired (a group including subjects with cochlear, neural and more central hearing losses), although no significant differences could be discovered between the subgroups. Palva concluded that speech discrimination tests in noise alone did not allow sufficient differentiation among various types of sensorineural deafness. He suggested that lowered speech discrimination ability in noise "appears to be useful in the diagnosis of perceptive deafness and in the evaluation of the handicap caused for instance by a noisy working place".

As part of a larger study, Ross, Huntington, Newby, and Dixon (1965) attempted to determine whether noise differentially affected the speech discrimination ability of a normal hearing group and a group with sensorineural hearing impairment, and to determine whether speech discrimination testing in noise had clinical utility. Recorded CID W-22 Auditory Tests were presented to each ear individually under headphones in quiet and mixed with white noise at a $+2.5 \mathrm{~dB}$ signal-to-noise ratio. The hearing impaired group demonstrated generally poorer speech discrimination 
functioning than the normal hearing group both in quiet and in noise. Although the relative discrimination shift from the quiet to the noise condition was equal for both groups, the hearing impaired group did demonstrate significantly greater variability for this discrimination shift (see Table I). These data failed to find significant differences between groups in the relative effects of noise on discrimination scores. Ross et al. suggested that different noise conditions and/or sensation levels of noise would result in greater speech discrimination differences in normal versus hearing impaired subjects.

Rupp and Phillips (1969) carried this investigation further, evaluating the interference functions of two kinds of noise and varied signal-to-noise ratios on the intelligibility of $\mathrm{W}-22$ word lists. They postulated that, as noise levels increased, the speech noise might differentially affect discrimination ability as compared with white noise interference for normal listeners. They reported that successful interpretation of speech signals decreased as either kind of noise increased and that speech-spectrum noise was markedly more interfering in its effects on discrimination ability than was white noise at equal signal-to-noise ratios (see Table II). Rupp and Phillips also reported that although some subjects who produced high intelligibility scores at low intensity levels maintained this performance throughout the task, other subjects who began to experience difficulty in interpreting speech early tended to reach very low scores quickly. They concluded that a number of individuals may have "normal-fragile" ears when listening under 
TABLE I

MEAN PERCENT CORRECT AND STANDARD DEVIATIONS FOR SCORES

ON CID W-22 AUDITORY TEST IN QUIET AND IN NOISE

FOR NORMAL HEARING SUBJECTS. $\mathrm{N}=30$

(ROSS ET AL., 1965)

\begin{tabular}{lllll} 
Measures & & Means & \multicolumn{2}{c}{ Standard Deviations } \\
\hline & $\begin{array}{l}\text { normal } \\
\text { hearing }\end{array}$ & hearing t-test & normal & hearing \\
& & F-test \\
& & & &
\end{tabular}

Discrim-

ination in $96.0 \% \quad 81.3 \% \quad 5.22 * \quad 3.0 \% \quad 15.3 \% \quad 26.37$ *

quiet

Discrim-

ination in $76.0 \% \quad 63.3 \% \quad 3.55+\quad 7.83 \% \quad 17.85 \% \quad 5.20$ *

noise

Relative

discrim-

ination

.22

.23

.41

.16

$.28 \quad 3.95+$

shift

* - significant at .05 level of confidence 


\section{TABLE II}

MEAN PERCENT CORRECT AND RANGES FOR SCORES ON CID W-22 AUDITORY TEST RELATED TO KINDS AND LEVELS OF NOISE

FOR NORMAL HEARING SUBJECTS. $\mathrm{N}=20$

(RUPP AND PHILLIPS, 1969)

Speech/Noise Levels in $d B$

$30 / 0$ white noise

$30 / 0 \quad$ speech noise

$30 / 20$ white noise

$30 / 30$ white noise

$30 / 30$ speech noise

$30 / 40$ white noise

$30 / 40$ speech noise

$30 / 50$ white noise

$30 / 50$ speech noise
Means

$100 \%$

$100 \%$

$90 \%$

$74 \%$

$66 \%$

$34 \%$

$6 \%$

$0 \%$

$0 \%$
Range

$92-100 \%$

-

$64-100 \%$

44-96\%:

$8-96 \%$

$4-76 \%$

$0-36 \%$

$0-20 \%$

$0-8 \%$ 
noisy conditions who "should be identified so that further assessment of subtle deficit may be made."

Experimenting with a new speech stimulus on normal listeners, Dirks and Bower (1969) investigated the effect of semantic content of a competing message on the identification of synthetic sentence material. Normal listeners ability to identify synthetic sentences (Speaks and Jerger, 1965) was measured monaurally under headphones in the presence of a passage of continuous discourse presented in the forward mode and again in the backward mode at varying signalto-noise ratios. The results indicated that sentence identification was similiar at all signal-to-noise ratios when the task was preformed with either a forward or reversed competing message (see Figure 1). Dirks and Bower concluded that this listening task was apparent1y unaltered by the disruptive features of the semantic content or meaning of the competing message, indicating that the masking efficiency of speech by competing speech "is due to the masking spectrum rather than the semantic properties of the competition."

Carhart and Tillman (1970) measured speech discrimination ability for monosyllables against competing sentences, postulating that individuals with sensorineural deficits find competing speech more disruptive than normal listeners or individuals with conductive hearing losses. Four groups of subjects (normals, conductives, sensorineurals with good discrimination ability in quiet, presbycusics with reduced discrimination ability in quiet) were each administered the Northwestern University (NU) Test 2 in a soundfield environment 
FIGURE 1

COMPARISON OF MEAN PERCENT CORRECT FOR SYNTHETIC SENTENCES IN FORWARD (CMF) AND BACKWARD (CMB) COMPETING MESSAGE FOR NORMAL HEARING SUBJECTS. $\mathrm{N}=8$

(DIRKS AND BOWER, 1969)

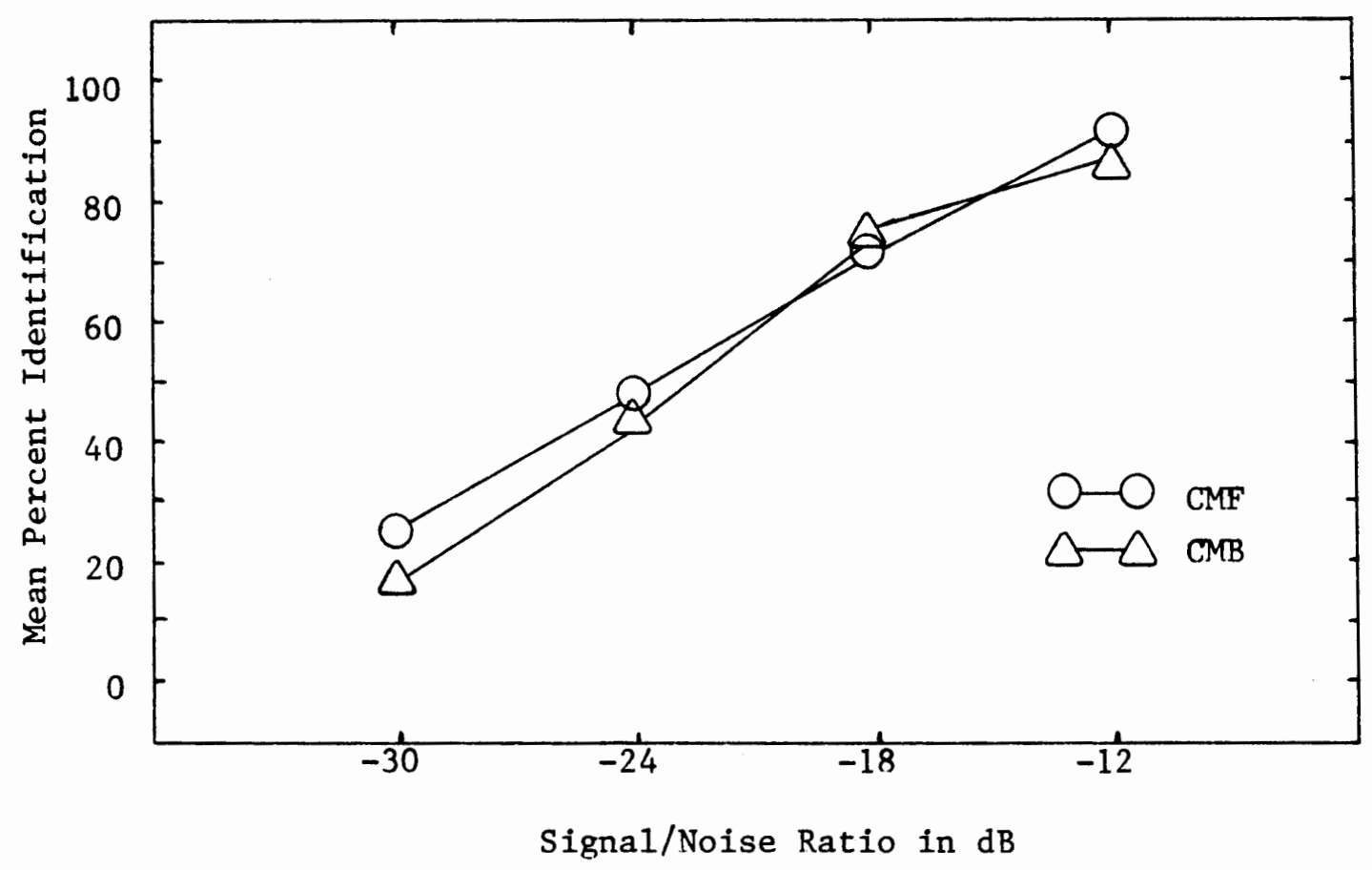


of competing sentences at varying signal-to-noise ratios. The data revealed that, in a competing message environment, individuals with sensorineural hearing impairments responded as though the masking produced by the background speech was substantially greater than that revealed by the performance of individuals with normal hearing or those with conductive losses (see Figure 2). The authors stated that in addition to traditional speech discrimination measures, "one must also specify the increase in masking efficiency of competing speech and of other background sounds that plague the patient when he is in complex listening environments" and stated a need to develop clinical tools that will measure such overmasking quickly.

In an attempt to refine the diagnostic potential of assessing speech discrimination ability in noise, Keith and Talis (1970) designed a study to determine whether the CID Auditory Test W-22 provided a more definative differential diagnosis of hearing impairments by testing in the presence of white noise. The speech discrimination ability of three groups of subjects (normal hearing, high frequency loss, flat loss) was assessed in a soundfield environment at three signal-to-noise ratios. Keith and Talis found a significant difference in discrimination scores between groups at $-8 \mathrm{~dB} S / \mathrm{N}$ and $0 \mathrm{~dB} S / \mathrm{N}$, the subjects with flat losses scoring poorer than those with high frequency losses (see Figure 3). They also reported a wide range of scores within all groups (see Figure 4) and concluded that this variability made virtually impossible the diagnosis of an individual's hearing impairment based on such discrimination 
FIGURE 2

MEAN PERCENT CORRECT FOR SCORES ON NU TEST 2 AS A FUNCTION OF SIGNAL-TO-NOISE RATIO FOR NORMAL HEARING, CONDUCTIVE, SENSORINEURAL, AND PRESBYCUSIC SUBJECTS.

(CARHART AND TILLMAN, 1970)

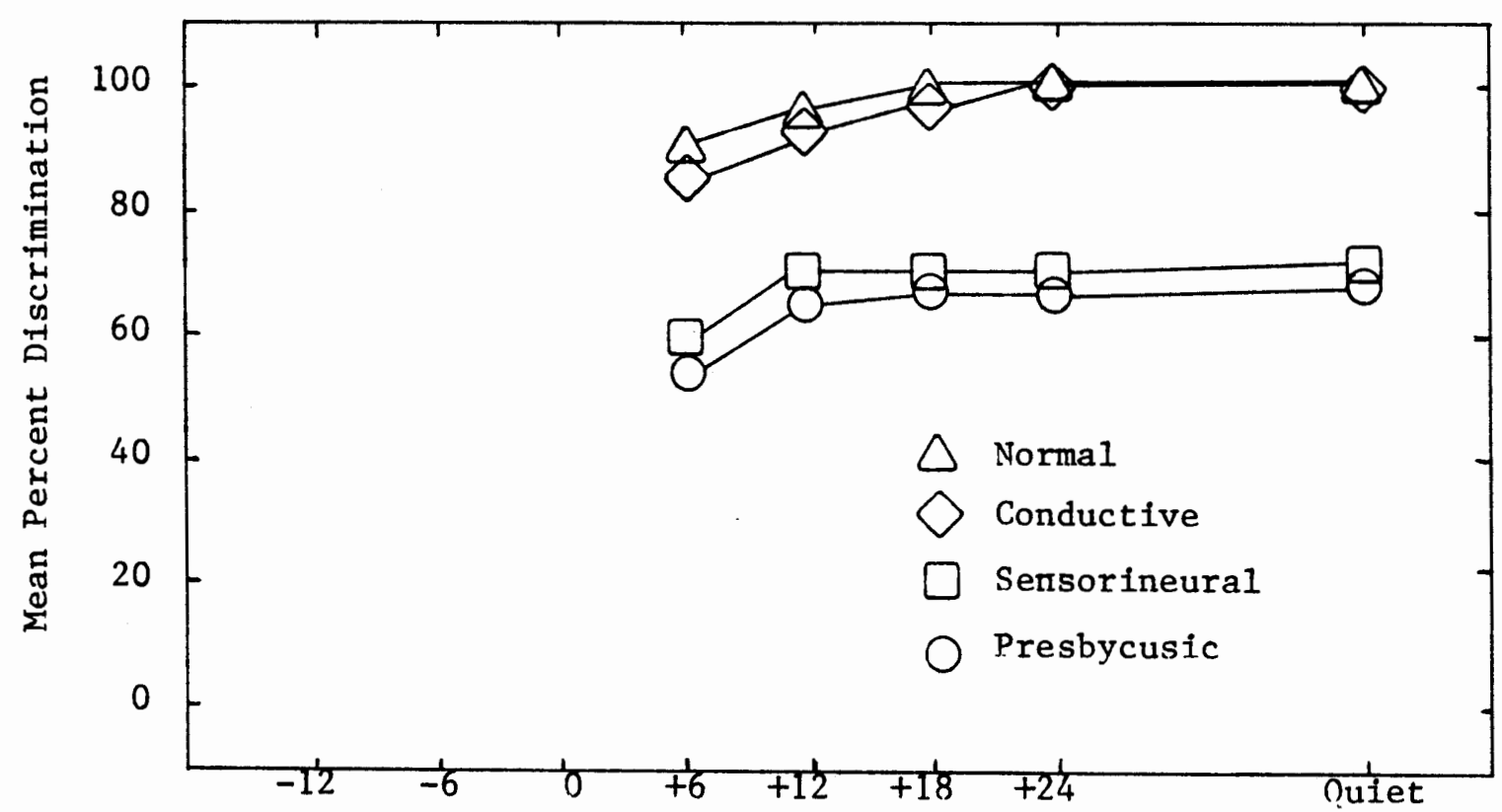

Signal/Noise Ratio in $d B$ 
FIGURE 3

MEAN PERCENT CORRECT FOR CID W-22 AUDITORY TEST AS A FUNCTION OF SIGNAL-TO-NOISE RATIO FOR SUBJECTS WITH NORMAL HEARING, HIGH FREQUENCY LOSSES AND FLAT LOSSES. $N=30$

(KEITH AND TALIS, 1970)

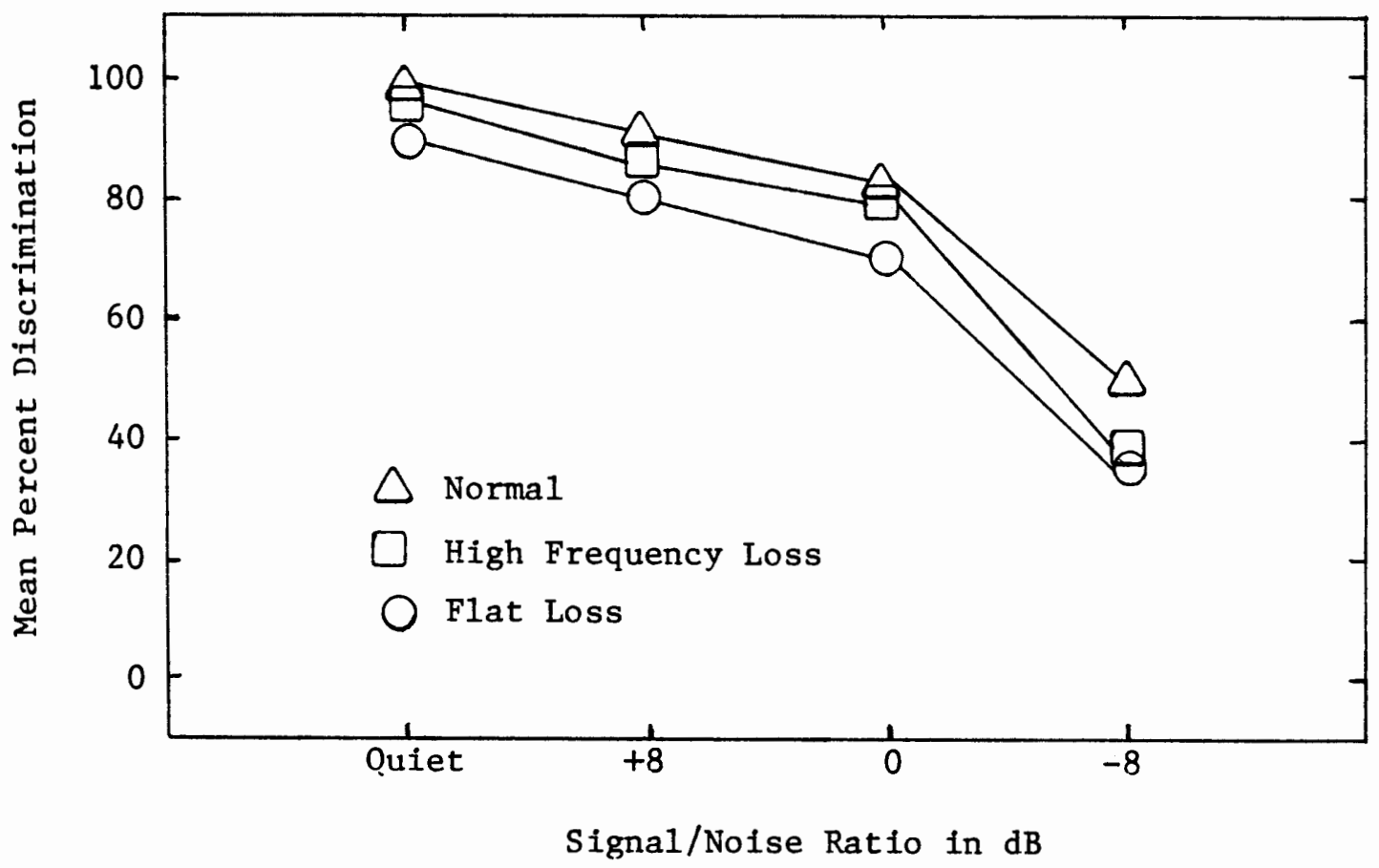


FIGURE 4

RANGES FOR CID W-22 AUDITORY TEST AS A FUNCTION OF SIGNAL-TO-NOISE RATIO FOR SUBJECTS WITH NORMAL HEARING, HIGH FREQUENCY LOSSES AND FLAT LOSSES. $\quad \mathrm{N}=30$

(KEITH AND TALIS, 1970)

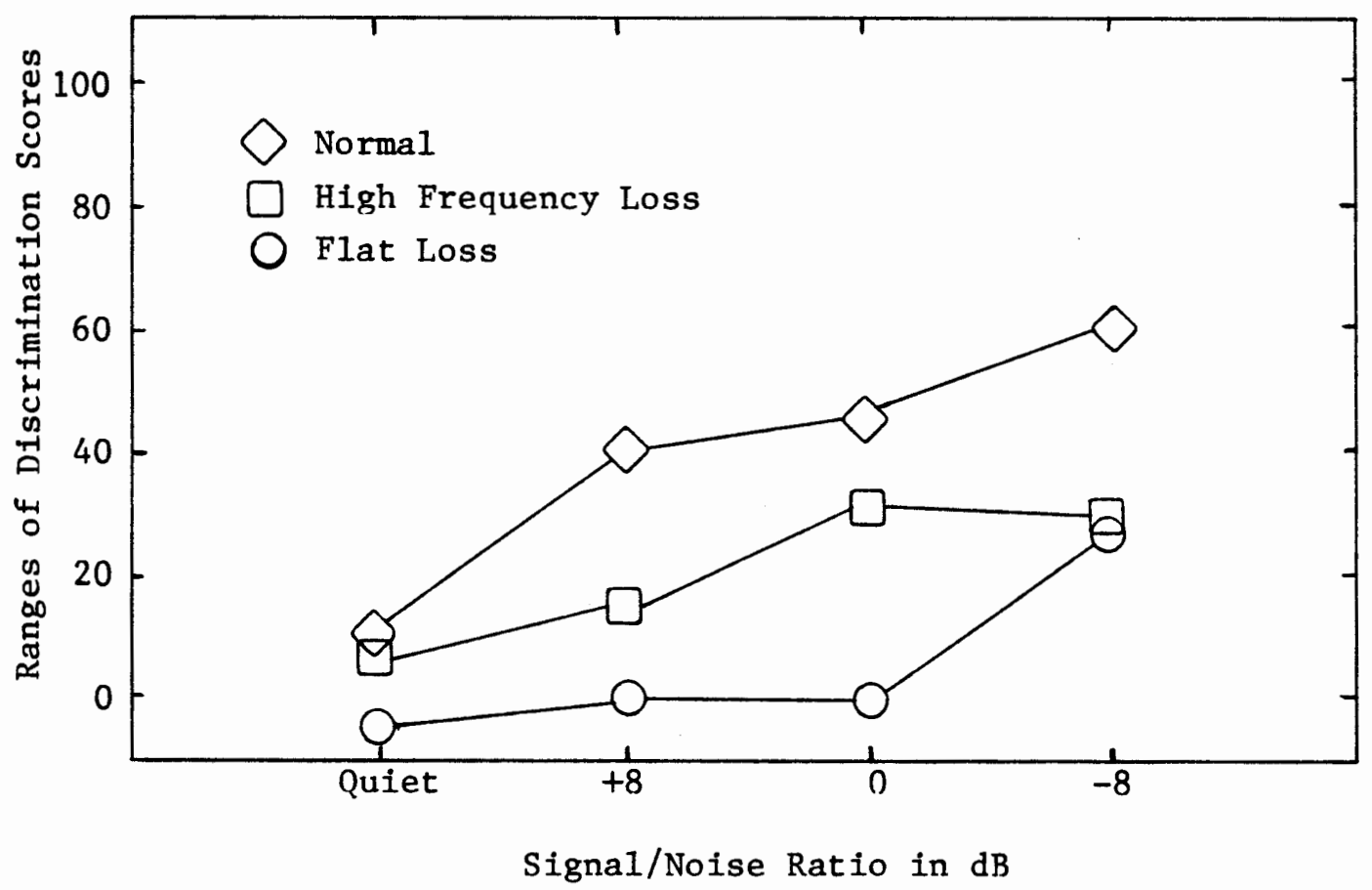


scores obtained in the presence of noise.

The data generated from a 1971 study by Cooper and Cutts extended the documentation of a reduced speech discrimination performance in noise by the sensorineurally impaired listener using another noise source for competition. These experimenters examined the speech discrimination ability of both normals and sensorineurals on CID W-22 and NU-6 word lists mixed with cafeteria noise and presented in a soundfield environment at varying signal-to-noise ratios. Analysis of mean performance data between groups indicated systematically inferior performance by the hearing impaired subjects at all signal-to-noise ratios (see Figure 5) and increased variability with low signal-to-noise ratios, especially in the hearing impaired group. The authors also stated that further exploration of discrimination in noise was "prerequisite to a fuller understanding of the problems faced by the impaired listener in his normal communication environment."

Jerger and Jerger (1974) investigated the effects of competing noise on the speech intelligibility ability of listeners with confirmed brain stem lesions. These experimenters presented the Synthetic Sentence Identification test stimuli (Jerger, Speaks and Trammel1, 1968) mixed in the same headphone with connected discourse (ICM) and in the headphone opposite the discourse (CCM) at varying signal-to-noise ratios. They found the ICM tasks on the side of the lesion produced consistantly poor performance in all subjects, whereas the CCM performance remained at $90 \%$ to $100 \%$ at all signalto-noise ratios. Although auditory findings varied considerably on 
FIGURE 5

MEAN PERCENT CORRECT FOR SCORES ON CID W-22 AUDITORY TEST AS A FUNCTION OF SIGNAL-TO-NOISE RATIO FOR NORMAL HEARING AND SENSORINEURAL SUBJECTS. $\mathrm{N}=16$ (COOPER AND CUTTS, 1971)

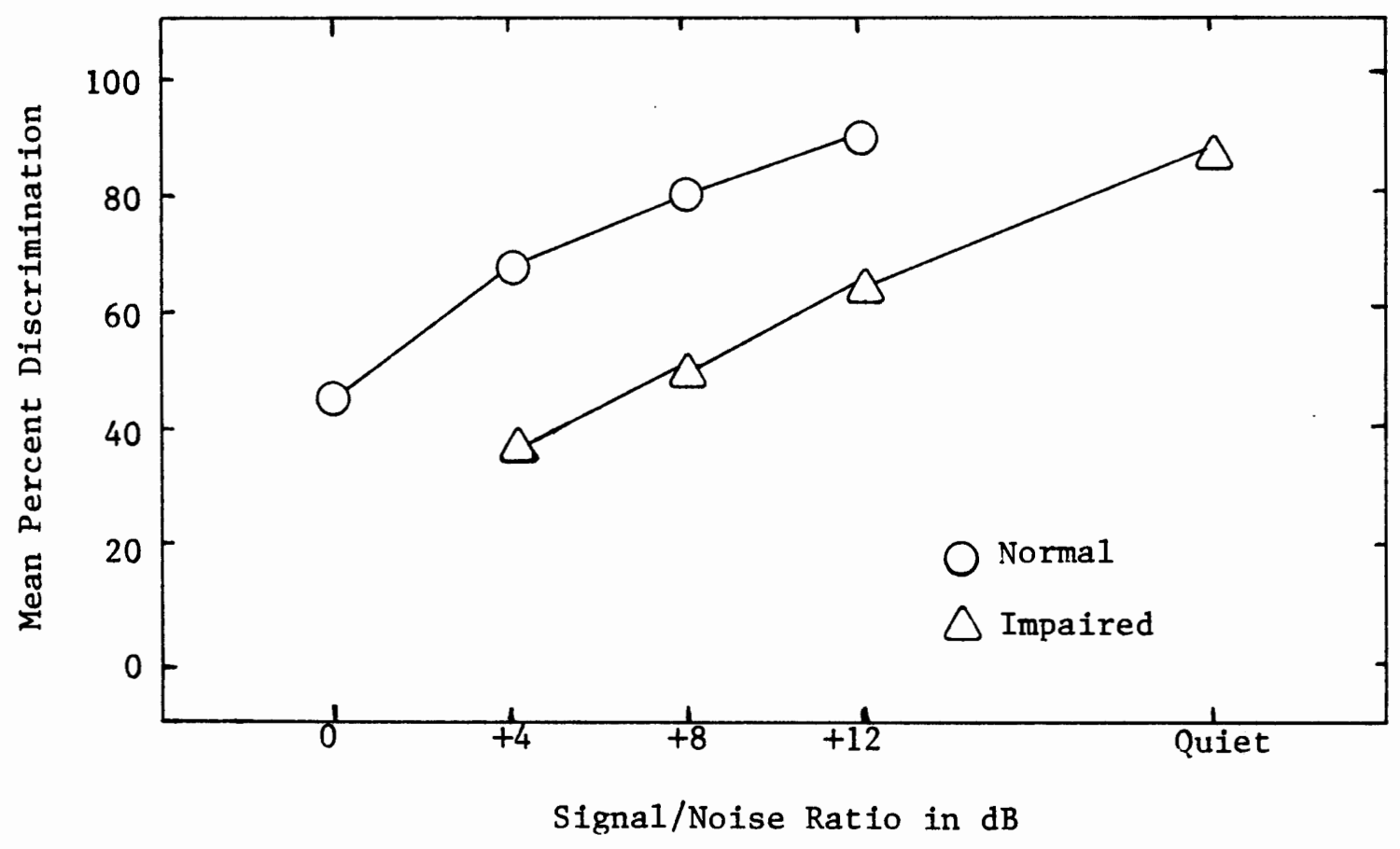


any one absolute index of auditory function for this group, Jerger and Jerger concluded that the SSI-ICM procedure was the only test yielding uniformly impaired performance in all of the subjects tested. The application of testing sentence identification in the presence of both ipsilateral and contralateral competing speech messages at different signal-to-noise ratios can thus aid in the differential diagnosis of brain stem lesions.

With the significance of assessing speech intelligibility performance in an environment of noise well established, only two major studies have sought to determine validation norms for speech discrimination scores on normal hearing listeners in noise. Kreul, Nixon, Kryter, Bell, and Lang (1968) selected the Modified Rhyme Test (House, Williams, Hecker, and Kryter, 1965) used in noise, believing it capable of rank-ordering listeners according to their ability to discriminate speech in everyday listening conditions. Eight normal hearing listeners were presented four Modified Rhyme Test (MRT) lists at $75 \mathrm{dBSPL}$ mixed with white noise in a soundfield environment at $+6,+8,+10$, and $+12 d B$ signal-to-noise ratios. From the results of this study, Kreul et a1. developed an estimated speech intelligibility gain function as shown in Figure 6 . They suggested that these data should produce an index of a listener's difficulty with speech intelligibility as well as differentiate performance for increasingly difficult listening conditions. In 1977, Doyle and Rupp proposed normative data for the assessment of speech discrimination ability using half lists of the CID W-22 Auditory Test. These lists were presented at $40 \mathrm{~dB}$ re SRT 
FIGURE 6

SPEECH INTELLIGIBILITY GAIN AS A FUNCTION OF SIGNAL-TO-NOISE RATIO FOR NORMAL HEARING SUBJECTS. $N=21$

(KREUL ET AL., 1968)

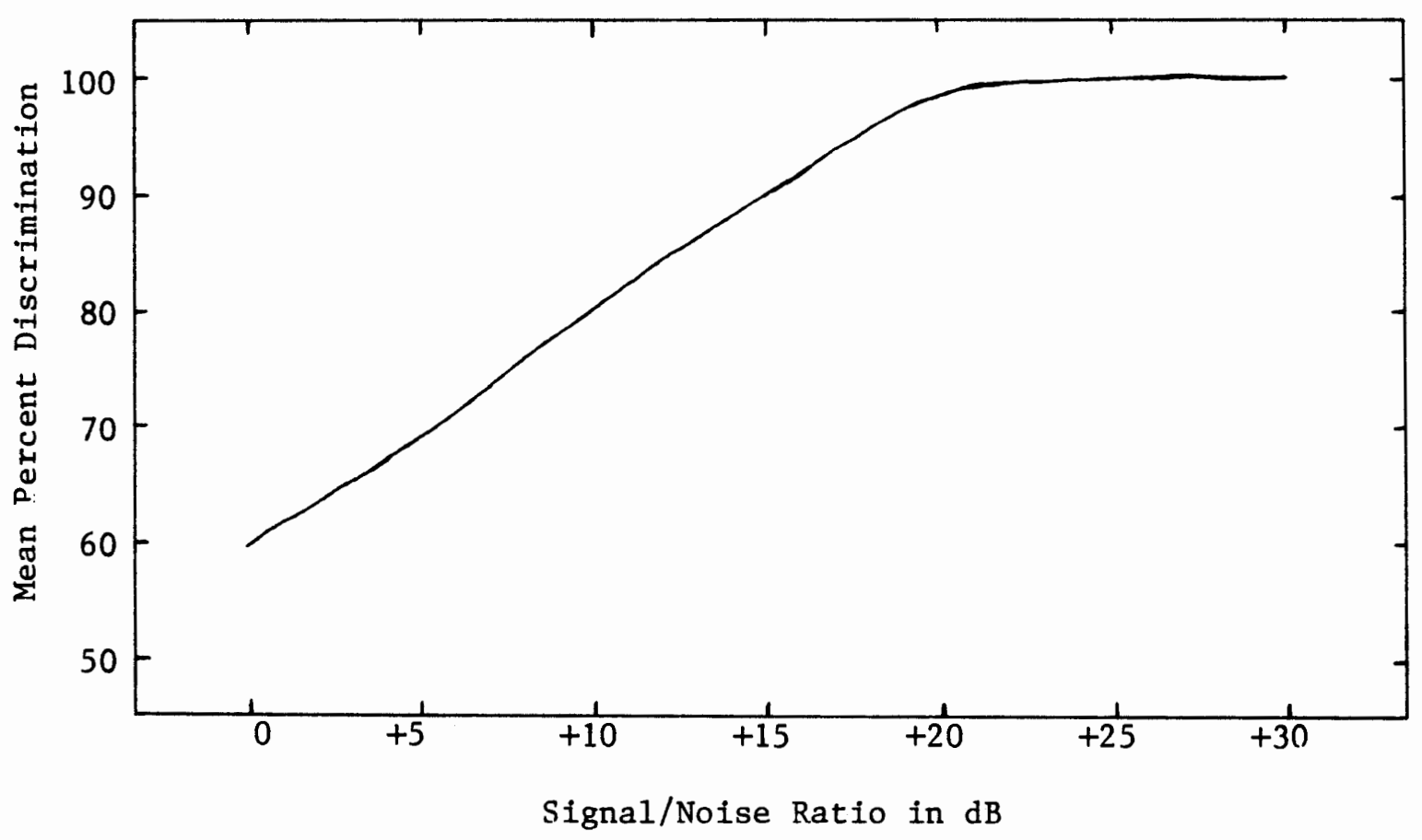


in the soundfield environment to twenty normal hearing subjects. The word stimuli were mixed with both wide-band and speech-spectrum noise adjusted in all cases to equal signal intensity $(0 \mathrm{~dB} S / N)$. The measures of central tendancy and variances for this group of subjects are reported in Table III. The authors proposed the underlined figures as provisional norms for clinical facilities using similiar conditions and employing similiar instrumentation.

\section{Speech Perception in Noise Test}

A test of speech intelligibility in noise using sentence materials with controlled word predictability was developed by Kalikow, Stevens and Elliott (1977) to improve on previous speechin-noise testing tools. The authors felt that these earlier tests failed to provide sufficiently close approximations to everyday communication situations and did not adequately assess or control the various components of the speech intelligibility process such as phonetic and prosodic factors, sentence context, word familiarity, noise interference, and 1istener-related factors. The major objective in developing this test was to produce a measure that would assess utilization of the linguistic-situational information of speech as well as utilization of acoustic-phonetic information. The authors hoped that such a sentence test would prove to be a more useful index of everyday speech intelligibility than a measure that assessed only acoustic-phonetic parameters of speech.

Sentence characteristics include a written response of the last word in each sentence and restrict the final word to a monosyllable to maintain a degree of acoustic control over the 


\begin{abstract}
TABLE III
MEAN PERCENT CORRECT, MEDIAN PERCENT CORRECT, RANGE, AND STANDARD DEVIATION OF SCORES ON CID W-22

AUDITORY TEST AT 0 DB S/N FOR NORMAL HEARING SUBJECTS. $\mathrm{N}=20$

(DOYLE AND RUPP, 1977)
\end{abstract}

In Wide-Band Noise

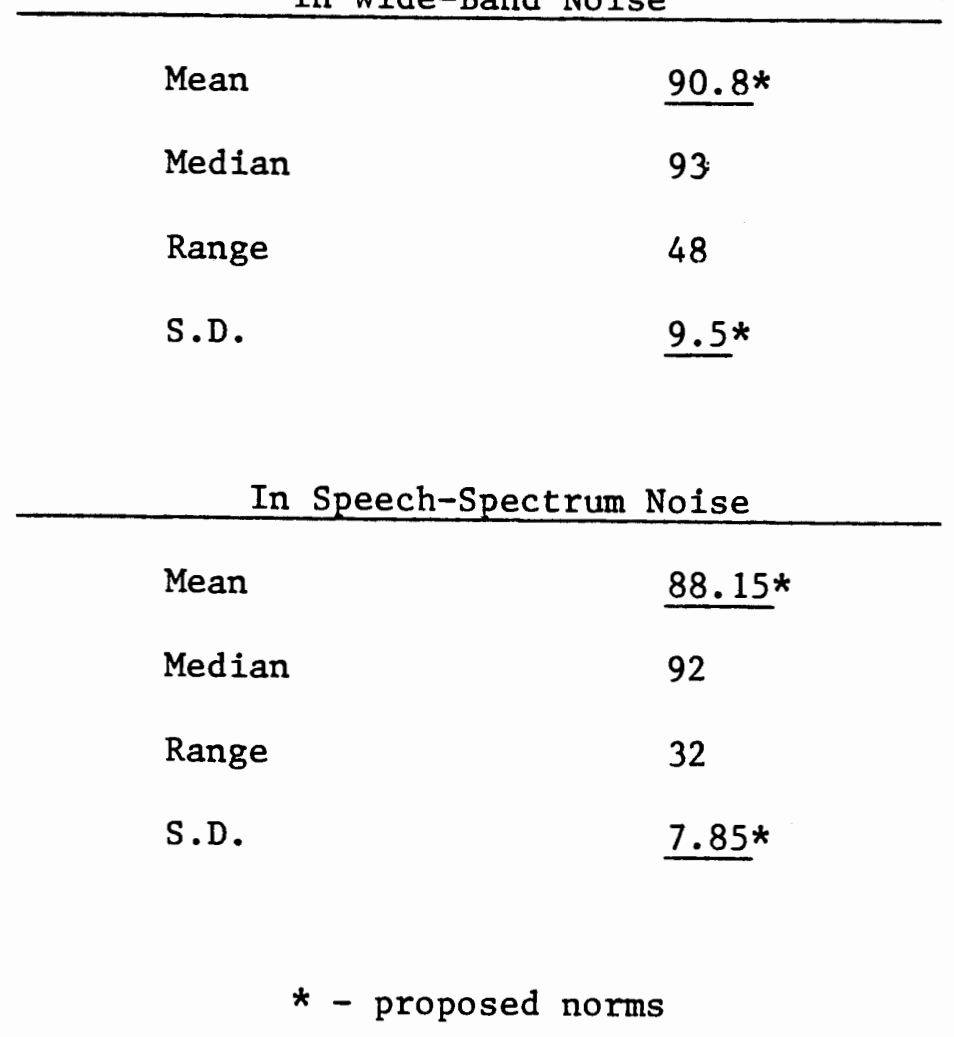


prosodic aspect of sentences. These final key words are neither little nor frequently used words in English. The sentence materials have a reasonable homogeniety in sentence length, constrained to five to eight words and six to eight syllables. The key words also have different degrees of predictability from the sentence context. If the predictability of the final word is high (HP), identification of the final word is aided by the semantic, prosodic and syntactic cues available in the sentence as well as by acoustic characteristics of the word itself (e.g., The boat sailed along the coast). When the key word has low predictability (LP) however, the 1istener must depend primarily on acoustic properties and lexical information regarding the key word itself (e.g., Miss Brown considered the coast). The current version of the test is comprised of eight equivalent forms of fifty sentences each, twenty-five HP and twenty-five LP sentences per form.

Twenty normal hearing subjects, divided into two groups age 18 through 25 and 60 through 75 years, provided normative data for this Speech Perception in Noise (SPIN) test. Both groups listened to different test forms presented at various signal-to-noise ratios using multi-talker babble from $-5 \mathrm{~dB} S / \mathrm{N}$ to $+10 \mathrm{~dB} \mathrm{~S} / \mathrm{N}$. The overall speech level was maintained at $80 \mathrm{dBSPL}$. The data revealed that both the HP and LP functions were lower for the older subjects than for the younger subjects (see Figure 7). The authors attributed this difference to a presumed greater hearing loss for the older subjects at high frequencies (above $4000 \mathrm{~Hz}$ ) and/or loss in cognative abilities for the older group. 


\section{FIGURE 7}

MEAN PERCENT CORRECT FOR SCORES ON HP AND LP SPIN TEST AS A FUNCTION OF SIGNAL-TO-NOISE RATIO FOR YOUNG AND OLDER

NORMAL HEARING SUBJECTS. $\mathrm{N}=20$

(KALIKOW ET AL., 1977)

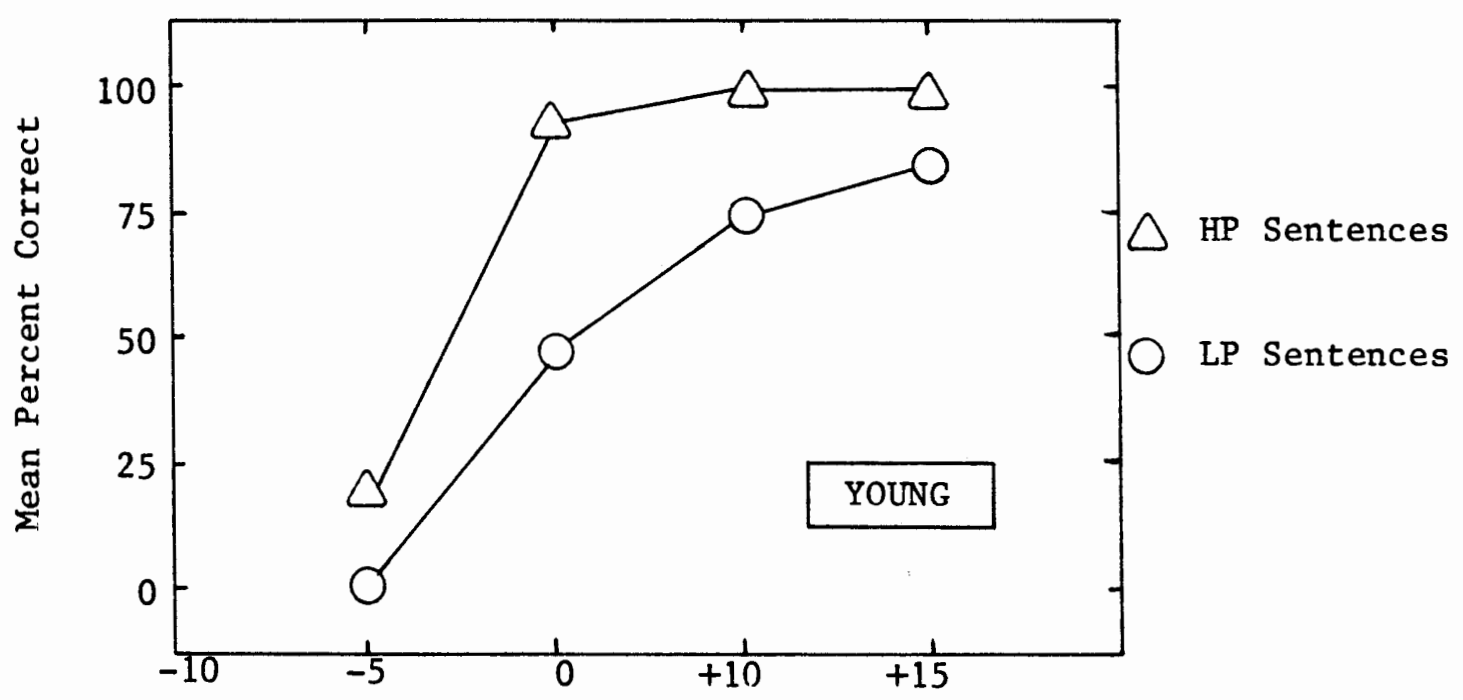

Signal/Noise Ratio in $d B$

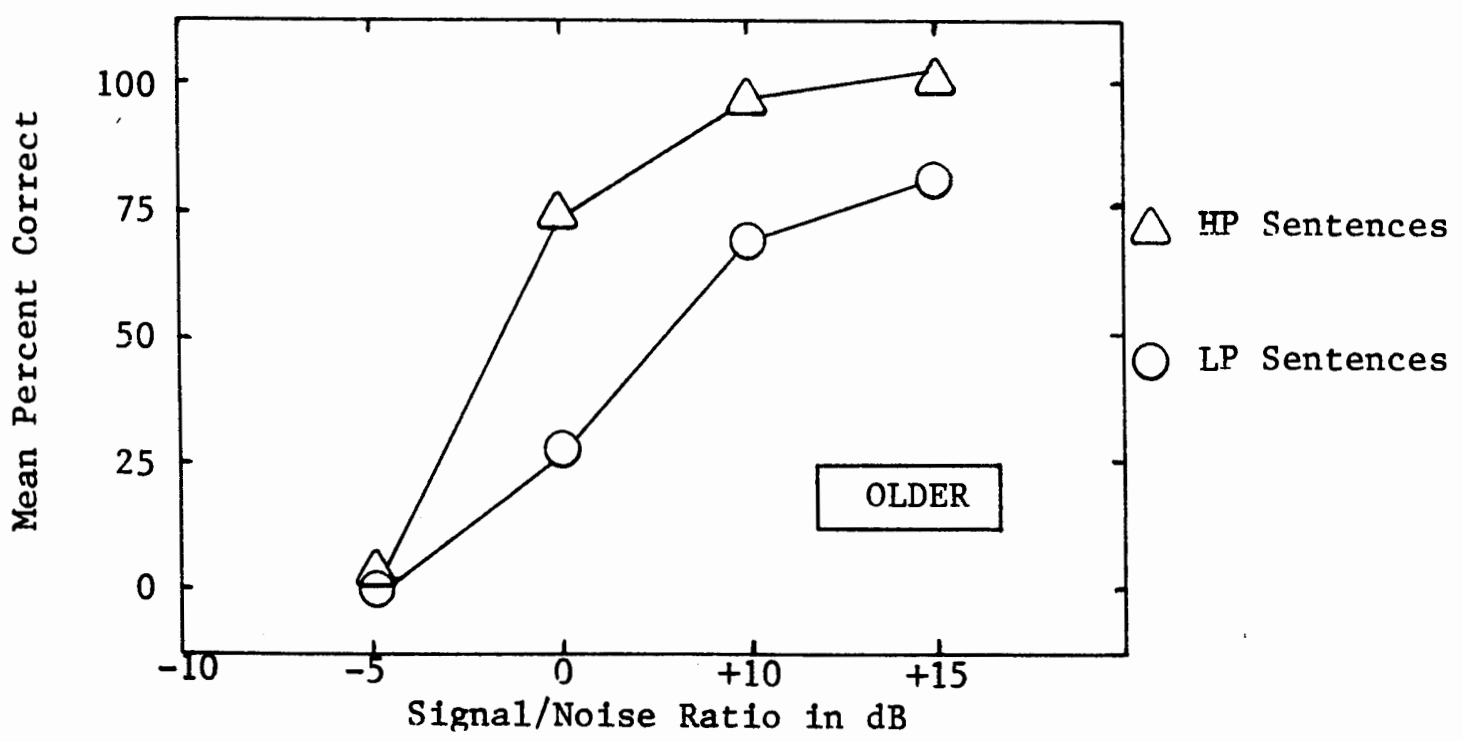


Kalikow et al. stated several potentially useful applications for the SPIN test. Scores on the HP and LP sentences have the potential of predicting the ability of hearing impaired individuals to perform in everyday communicative situations and may thus help to estimate the benefit that these individuals will gain from a hearing aid. It may also assess the involvement of cognitive and memory processes in individuals suspected of deficiencies in these aspects of communication. A related application may be in testing the comprehension of English for those learning it as a second language. Finally, the SPIN test may be used for evaluating the benefit derived from nonauditory aids for those with severe or profound hearing losses.

\section{Summary}

The assessment of speech discrimination ability is an important part of the audiologist's diagnostic test battery. Performance on speech tasks helps to determine the amount of difficulty an individual has understanding everyday speech as well as to provide information differentiating normal listeners from those with hearing impairments. Speech testing also aids in the diagnosis of ear disease. Finally, speech intelligibility scores form the basis of comparing performances of different hearing aids.

Several materials and methods have been developed to measure speech discrimination ability. Phonetically balanced monosyllabic words were the first speech stimuli put to clinical practice and are still widely used today. Forms of connected discourse, including sentences, also receive clinical application. Most recently, these 
speech stimuli have been presented in the presence of various background noises to more accurately replicate everyday listening environments.

The assessment of speech discrimination performance in noise is especially significant in testing individuals with hearing pathologies. Several experiments have provided substantial data documenting the markedly degraded speech discrimination ability of those individuals with sensorineural pathology as compared with normal hearing listeners or those with conductive hearing impairments. Certain speech-in-noise tests, used in concert with other audiologic information, aid in the differential diagnosis of retrocochlear lesions. Still other speech intelligibility tools, mixed with noise, may provide measures of the memory and cognitive processes of speech perception.

\section{PURPOSE}

The purpose of this investigation was to measure the ability of young normal hearing listeners to perceive speech in the presence of a background noise which varies in the relative intensity of its semantic content.

\section{Rationale}

There are many reasons why oral communication may be insufficient or fail completely. The context may not provide adequate meaning, the listener may confuse certain sounds with others or not hear these sounds at all, the listener may have a hearing loss, or the speech may be masked by environmental noises. 
Careful evaluation of the relative importance of each of these factors on the intelligibility of speech helps to assess the realistic extent of hearing impairment for everyday communication. Data have been collected demonstrating the diagnostic and rehabilitative importance of examining speech discrimination ability in noise. Several speech stimuli (monosyllables, connected discourse, sentences), different competing noises (white noise, speech-spectrum noise, cafeterla noise, multi-talker babble, single-speaker connected discourse), and various signal-to-noise ratios (ranging from $-40 \mathrm{~dB} S / \mathrm{N}$ to $+30 \mathrm{~dB} \mathrm{~S} / \mathrm{N}$ ) have all been employed in many combinations to measure this ability. Systematic analysis of the parameter of semantic content or meaning of the competing noise has been reported only once (Dirks and Bower, 1969) suggesting that the target speech identification task was not significantly altered by the features of meaning in the competing message.

Understanding the ability of competing speech to disrupt oral communication is important, for it is in this acoustic environment that most everyday communication occurs. The failure of Dirks and Bower to find a significant masking effect of semantically loaded competing discourse may be due to the type of highly predictable primary speech stimulus used (closed-set) and/or the ability of the subjects to perceive an identifying key word during the natural prosodic pauses in the competing discourse (Martin and Musse11, 1979). Further, the ability of a listener to perceive sentences with low predictive value may differ significantly from the listener's ability to perceive highly predictable sentences in 
competing speech of equal or less semantic content.

The knowledge that semantic content or meaning may normally interfere with the intelligibility of some communication and not others has great value. If the ability of certain listeners to perceive speech varies from this normal function, the audiologist may have additional diagnostic information to support a cochlear, brain stem or even cortical site of lesion. A more realistic comparison of hearing aid benefit may also be performed using low predictability stimuli mixed with a background of highly meaningful discourse. Finally, children with suspected learning disabilities may be evaluated in conditions of increasing semantic content and compared with normal learners for distractability, earedness and other factors that cumulatively reflect yardsticks for intervention. 
CHAPTER III

METHODS

\section{Subjects}

Thirty normal hearing volunteer subjects ages 18 though 30 years were selected from Portland State University basic speech communication classes. Subjects received an audiologic assessment under headphones using standard clinical procedures prior to selection for this study and were found to have air conduction thresholds of $15 \mathrm{dBHL}$ or better for the octave test frequencies 250-8000 Hz (ANSI, 1969) in each ear. Speech discrimination scores in quiet were at least $90 \%$ in each ear for all subjects when delivered monaurally at a comfortable 1istening level. In addition, performance intensity function $(P I P B)$ results were at least $90 \%$ in each ear for al1 subjects when delivered monaurally at 95 dBHL. Subjects selected for this study also reported negative histories of significant middle ear problems, familial deafness and excessive noise exposure as well as a lack of familiarity with the experimental stimulus materials. Each subject reported English to be his/her native language.

Procedure

Subjects were seated in a chair facing two soundfield speakers in the audiologic test suite, positioned one meter from and at a 0

45 angle to each speaker. Subjects were given a pure tone air 
conduction screening under headphones at octave test frequencies 250-8000 $\mathrm{Hz}$ to confirm his/her inclusion in this investigation. Subjects then removed the headphones and were read the following instructions via the soundfield system:

You will hear both a story and some sentences presented at the same time. Your task is to write down the last word in each sentence. Listen for the announcer's cue introducing the sentences then write the last word of each sentence on the paper. If you're not sure about the word, either guess or draw a line through the numbered blank. After you've finished each answer sheet, remove it from the clipboard and place it face-down on the floor. Do you have any questions?

The experimental testing material consisted of a prerecorded two-component noise complex and a prerecorded Speech Perception in Noise (SPIN) test 1ists 2.1 through 2.6 (Kalikow et al., 1977). The two-component noise complex was comprised of speech noise ( $\mathrm{SpN}$ ), which has a spectral composition limited to the speech frequencies $(500-2000 \mathrm{~Hz})$, and a narrative (Na) about a WWII veteran (Korzybski, 1960) recorded in male voice on a reel-to-reel tape (Maxell, Model LN35-90). These stimuli were mixed and rerecorded so that the six narrative-to-speech noise $(\mathrm{Na} / \mathrm{SpN})$ conditions altered in intensity in $2 \mathrm{~dB}$ increments from a $-2 \mathrm{~dB} \mathrm{Na} / \mathrm{SpN}$ to a $+8 \mathrm{dBNa} / \mathrm{SpN}$. The overall intensity of the $\mathrm{Na} / \mathrm{SpN}$ complex remained constant, varying in intensity $\pm_{5} \mathrm{~dB}$. The six 50 -item SPIN sentence lists were also recorded in male voice on a cassette tape (Maxe11, Model UDXLI-C90), varying in intensity $\pm_{5} \mathrm{~dB}$. A $1000 \mathrm{~Hz}$ tone was recorded on both tapes at this time to insure calibration. Subjects were presented each of the six SPIN sentence lists at a different $\mathrm{Na} / \mathrm{SpN}$ ratio. The order in which the $\mathrm{Na} / \mathrm{SPN}$ ratios and the SPIN 1ists appeared were 
randomly determined for each subject by Graeco-Latin Square design (Winer, 1962).

The $\mathrm{Na} / \mathrm{SpN}$ complex was delivered to the soundfield

environment at a constant $60 \mathrm{dBSPL}$ (re $20 \mathrm{~Pa}$ ), varying $\pm_{2} \mathrm{~dB}$. The SPIN stimuli sentences were added to the $\mathrm{Na} / \mathrm{SpN}$ complex with an overall +8 dB signal-to-noise advantage (Licklider and Miller, 1951). The experimental stimuli were then mixed in the audiometer and presented simultaneously to the subjects binaurally through the soundfield system.

\section{Instrumentation}

Al1 tests were conducted in a double-walled sound treated room (International Acoustics Corporation, Model 1403) and through a dual channel clinical audiometer (Maico, Model 24B). A11 air conduction testing was presented through a standard clinical set of headphones (Telephonics, Model TDH-39) mounted in foam rubber cushions (Acoustic Research, Model MX 41/AR). Soundfield stimuli were presented to two 50-watt power amplifiers (Mackintosh, Model MC-50), then through a sound speaker system (Maico, clinical model).

Experimental stimuli consisted of the $\mathrm{Na} / \mathrm{SpN}$ competing noise complex delivered to the audiometer by a reel-to-reel stereo tape recorder (Sony, Mode1 TC-377) at $7 \frac{1}{2}$ inches per second. The SPIN sentences were delivered to the same audiometer by a cassette stereo tape recorder (Technics, Model RS-263AU). The audiometer's calibrated tape circuit was utilized to insure the electrical and acoustic integrity of the experimental stimuli. 


\section{Calibration}

The audiometer output at the headphones for both right and left channels was electroacoustically calibrated to reflect current ANSI standards for pure tones (S3.6-1969) using a precision sound level meter (Bruel and Kjaer, Model 2203) and an artifical ear (Bruel and $\mathrm{Kjaer}$, Mode1 4152). The audiometer output at the speakers for both speech circuits was electroacoustically calibrated according to the procedures established by Wilbur (1978). A prerecorded segment of a $1000 \mathrm{~Hz}$ pure tone was utilized to calibrate the speech circuit. The tape recorded stimulus materials were presented through the audiometer's tape and accessory circuits with the calibration tones centered at $0 \mathrm{dBHL}$ on both $\mathrm{VU}$ meters. 
CHAPTER IV

RESULTS

The purpose of this study was to measure the ability of young normal hearing listeners to perceive speech in the presence of a background noise which varies in the relative intensity of its semantic content. The experimental group consisted of thirty normal hearing adults, 10 males and 20 females. Ages ranged from 18 to 30 years, with a mean age of 23.7 years.

All computations on the data were performed on a Honeywell 6620 computer using the SPSS subprogram "Reliability" for the application of the data to a repeated measures analysis of variance (Hull and Nie, 1979). T-tests were also performed on the Honeywell computer using the SPSS subprogram "T-test" (Nie, Hull, Jenkins, Steinbrenner, and Bent, 1975).

Performance scores were obtained for all subjects on both the high predictability (HP) and low predictability (LP) SPIN sentences mixed with a competing message varying from a $-2 \mathrm{~dB}$ narrative-to-speech noise ratio $(\mathrm{Na} / \mathrm{SpN})$ to a $+8 \mathrm{~dB} \mathrm{Na} / \mathrm{SpN}$. The raw data were analyzed and the means and variances were determined for each condition. Means ranged from $99.60 \%$ correct at $-2 \mathrm{~dB}$ $\mathrm{Na} / \mathrm{SpN}$ to $98.80 \%$ correct at $+8 \mathrm{~dB} \mathrm{Na} / \mathrm{SpN}$ for the HP sentences and from $97.07 \%$ correct at $-2 \mathrm{~dB} \mathrm{Na} / \mathrm{SpN}$ to $87.87 \%$ correct at $+8 \mathrm{~dB}$ $\mathrm{Na} / \mathrm{SpN}$ for the LP sentences (see Figure 8 ). These mean performance 
scores compare favorably to both the HP and LP scores reported originally by Kalikow et al. (1977) using the SPIN test with young listeners at a $+10 \mathrm{~dB}$ overall signa1-to-noise ratio. Data reported by Kreul et al. (1968), Carhart and Tillman (1970), Keith and Talis (1970), and Cooper and Cutts (1972) indicate poorer performance on traditional monosyllabic word discrimination tests generated by normal hearing samples at equivalent overall signalto-noise ratios using various competing noise sources. Sentence intelligibility is higher than corresponding word intelligibility (Egan, 1948), thus this discrepancy in performance scores between the HP sentences and monosyllabic words supports pervious experimental conclusion.

The mean error scores and standard deviations for both the $\mathrm{HP}$ and LP sentences at each $\mathrm{Na} / \mathrm{SpN}$ ratio were treated with a repeated measures analysis of variance (see Table IV). This analysis revealed that there was no main effect for the $\mathrm{Na} / \mathrm{SpN}$ ratios on the high predictability sentences $(F=1.27)$. However, the $\mathrm{Na} / \mathrm{SpN}$ ratios did produce a significant effect on the low predictability sentences $(F=11.29)$ beyond the .001 level of confidence. Further analysis demonstrated a similiar lack of effect of the $\mathrm{Na} / \mathrm{SpN}$ ratios on the HP standard deviations $(\mathrm{F}=1.27)$, whereas the LP standard deviations were significantly effected by the $\mathrm{Na} / \mathrm{SpN}$ ratios $(\mathrm{F}=11.29)$ beyond the .001 level of confidence. The significant interference effect of the $\mathrm{Na} / \mathrm{SpN}$ ratios on the LP mean performance and standard deviation differences suggests that the ability of the experimental group to understand 
TABLE IV

MEAN ERRORS AND STANDARD DEVIATIONS FOR SCORES

ON HP AND LP SPIN SENTENCES AT NA/SPN RATIO

FOR EXPERIMENTAL GROUP. $\mathrm{N}=30$

\begin{tabular}{llccc}
$\mathrm{Na} / \mathrm{SpN}$ & \multicolumn{2}{c}{ HP Sentences * } & \multicolumn{2}{c}{ LP Sentences** } \\
\hline-2 & mean & S.D. & .73 & .94 \\
0 & .10 & .31 & 1.0 & 1.1 \\
+2 & .10 & .31 & 1.4 & 1.3 \\
+4 & .13 & .43 & 1.9 & 1.6 \\
+6 & .23 & .43 & 2.1 & 1.2 \\
+8 & .10 & .31 & 3.0 & 2.3 \\
& .30 & .65 &
\end{tabular}


communication in a noisy environment was partly a function of the linguistic and prosodic cues available in everyday conversation. When sentence completion was not predictable, a competing message not only adversely affected the perception of the sentences, but also created a significant variation in the number of stimuli perceived to be correct.

Increasing the relative intensity of the semantic content in the competing message produced a similiar increase in the mean number of performance errors and standard deviations for the LP sentences. Mean performance errors and standard deviations for the $\mathrm{HP}$ sentences remained relatively constant with increasing $\mathrm{Na} / \mathrm{SpN}$ ratios (see Figure 9). This linear progression deviates at $+6 \mathrm{db}$ $\mathrm{Na} / \mathrm{SpN}$ for the HP mean errors and standard deviations and for the LP standard deviations, perhaps due to a slight reduction in the overall SPL of the $+6 \mathrm{~dB} \mathrm{Na} / \mathrm{SpN}$ on the master tape causing a more adverse overall signal-to-noise ratio at that experimental condition. However, the general trend remains such that increases in the semantic content of the competing message produced increasingly lower and increasingly more variant performance scores on speech stimuli with minimal predictive value. Sentence understanding based on multiple predictive cues appeared relatively unaffected by semantically loading the competing noise at least within the limits of this study. These results agree with Dirks and Bower (1969) who also reported that semantic content did no disrupt sentence identification. As in this investigation, their experimental stimuli were of such a highly predictive nature that semantically loaded 
FIGURE 9

MEAN ERRORS AND STANDARD DEVIATIONS ON HP AND LP. SPIN TEST AS A FUNCTION OF NA/SPN FOR EXPERIMENTAL GROUP.

$\mathrm{N}=30$
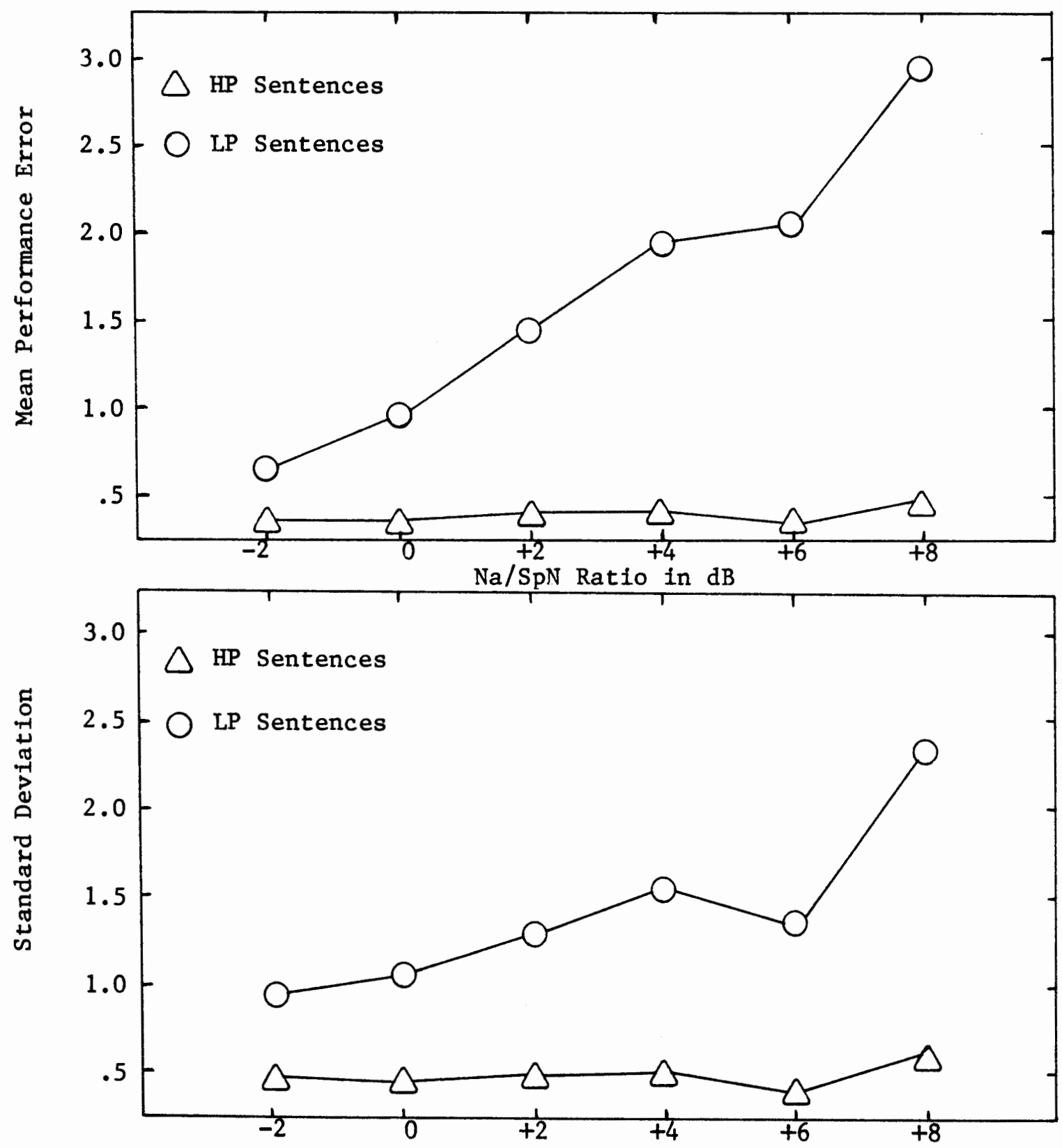
discourse had little effect on the primary listening task. Finally, the mean error scores for the HP and LP sentences were paired at equivalent $\mathrm{Na} / \mathrm{SpN}$ ratios and the intrapair differences analyzed. Significant differences were found between the HP and LP mean error pairs at each $\mathrm{Na} / \mathrm{SpN}$ ratio, differences exceeding the .001 level of confidence (see Table V). Similiar to the increase in mean error scores and standard deviations with increased semantic content of the competing message, the $t$ values became more robust with each succeeding $\mathrm{Na} / \mathrm{SpN}$ ratio. The $t$ value at the $+6 \mathrm{~dB} \mathrm{Na} / \mathrm{SpN}$ remained outside this linear progression, although the general interference trend of the semantic content also appears to remain stable for these data. 
TABLE V

MEAN ERROR PAIRS AND T VALUES FOR DIFFERENCES

AT NA/SPN FOR EXPERIMENTAL GROUP. $N=30$

$\mathrm{Na} / \mathrm{SpN}$

$-2$

0

$+2$

$+4$

$+6$

$+8$

$\begin{array}{rr}\text { HP } & .30 \\ \text { LP } & 3.03\end{array}$

* - significant at .001 level of confidence $t$ value

$\begin{array}{ll}\text { HP } & .10 \\ \text { LP } & .73\end{array}$

$3.74 *$

$\mathrm{HP} \quad .10$

LP 1.03

$4.47 *$

HP $\quad .13$

$6.20 *$

LP 1.43

HP .23

LP 1.97

$6.30 *$

HP .10

$9.81 *$

LP 2.07

7.69* 
CHAPTER V

\section{DISCUSSION}

This study employed the Speech Perception in Noise test mixed with a semantically variable competing message to assess the ability of young normal hearing listeners to discriminate speech in noise. The investigation attempted to simulate a typical everyday listening situation by presenting the experimental stimulus in an environment of background noise and by varying the relative intensity of the semantic content of the competing noise. The results indicated that background noise of a highly meaningful nature interfered significantly with the understanding of low predictability primary messages, but failed to degrade performance on items of high predictability.

Analysis of these data revealed that the competing message interfered significantly with the perception of the low predictability stimuli at all $\mathrm{Na} / \mathrm{SpN}$ ratios examined, but had no significant effect on highly predictable stimuli. The competing message also interacted significantly with the variability of error scores produced on the LP sentences with no effect on HP sentence error variability. The experimental listeners not only produced more incorrect scores on the LP sentences, but the range of alternative word responses was greater than that recorded on the HP sentences. The acoustic, syntactic, semantic, lexical, and prosodic properties of the HP 
sentences therefore appear to have collectively provided enough cues for relatively easy and consistent sentence perception even in an adverse listening situation. These listeners could not, however, overcome the interfering nature of the competing message to understand sentences based exclusively on limited acoustic and lexical cues.

This interference effect on the sentences of low predictive value appears to be systematic and linear. Each increase in both the number of errors and in the variability of these errors corresponded directly to a similiar increase in the semantic content of the competing message. Not only did increased semantic loading, of the noise source interrupt successful perception of the primary message, but the task became succeedingly more interruptive as the semantic load was intensified. This suggests that semantically loaded competing noise interferes with the encoding process for primary messages as a direct function of the competition ratio, at least within the signal-to-noise ratios employed in this study.

This encoding process may be interrupted for a variety of reasons. The perception of unsolicited and/or vague statements may require complete utilization of linguistic-situational cues in addition to acoustic-phonetic information, especially in adverse listening environments which mask most of these normal speech cues. Although research data prove older individuals and hearing impaired listeners perform poorly on speech-in-nolse tasks, young intact listeners may also normally experience similiar difficulties insofar as the inhibition of certain highly propositional background noises. 
Unpredictable sentences presented in competition with meaningful discourse have proven such a task. In addition, the encoding process of at least some listeners may be interrupted as a result of possible subtle deficiencies in normal auditory processing function.

Three problems with the test stimuli and experimental procedure arose during this investigation. Most obvious are the discrepancies in both HP and LP mean scores and standard deviations at $+6 \mathrm{~dB} \mathrm{Na} / \mathrm{SpN}$ revealed by the data. Although the SPL of the $\mathrm{Na} / \mathrm{SpN}$ complex was continually monitored during preparation of the experimental tape, a decrease in the overall intensity of the recording may have occurred. Despite recent calibration, any momentary deviation in the linearity of the audiometer, speakers, tape recorders, and/or sound level meter could have affected the $\mathrm{Na} / \mathrm{SpN}$ recording or presentation. Interaction between the SPIN stimuli and the $+6 \mathrm{~dB} \mathrm{Na} / \mathrm{SpN}$ competition ratio was highly unlikely as randomization was insured by application of the Graeco-Latin Square research design.

The length of time necessary to administer this experiment is also a cause of concern. Including the brief pure tone air conduction screening, no subject was able to complete the task in less than 45 minutes. In spite of verbal reinforcement offered after every other SPIN list presentation, subjects reported the onset of fatigue, inattentiveness and restlessness. Future application of these procedures to a geriatric or school-aged population necessitates streamlining the test to accomodate 
shortened attention spans.

Finally, the selection of key words in the eight forms of the SPIN test currently available should be examined regarding answer bias. Many final key words are repeated in both the HP and LP contexts. When asked by the examiner if they had guessed on any responses, subjects reported that they were certain of the last words in some ambiguous (LP) sentences because they had previously heard these words in another unambiguous (HP) context. The GraecoLatin Square research design and sample size controlled for any significant effect these repeated words may have had on this study. These key words should be investigated, however, if the experimental design or the stimuli employed are amended in a future study.

\section{Conclusion}

The purpose of this investigation was to measure the ability of young normal hearing listeners to perceive speech in the presence of a background noise which varies in the relative intensity of its semantic content. The Speech Perception in Noise test was mixed with a two-component competing noise complex in which the narrative-to-speech noise ratio varies in $2 \mathrm{~dB}$ increments from a $-2 \mathrm{~dB} \mathrm{Na} / \mathrm{SpN}$ to a $+8 \mathrm{~dB} \mathrm{Na} / \mathrm{SpN}$. These stimuli were presented at an overall $+8 \mathrm{~dB}$ signal-to-noise ratio to thirty young normal hearing adults through the soundfield system. The differences between the mean error scores and standard deviations for the low predictability sentences were found to be statistically significant at all $\mathrm{Na} / \mathrm{SpN}$ ratios. No main effect was observed for the $\mathrm{Na} / \mathrm{SpN}$ ratios on the high predictability sentences. Significant differences 
were also observed between the mean error scores and standard deviations of HP and LP pairs at each $\mathrm{Na} / \mathrm{SpN}$. The data further revealed a systematic increase in the LP mean error scores and standard deviations as a result of linear increases in the $\mathrm{Na} / \mathrm{SpN}$ ratio. These results suggest that semantically loaded competing noise significantly influences the perception of primary messages as a direct function of the competition ratio.

Since the $\mathrm{Na} / \mathrm{SpN}$ ratios for the high predictability sentences and low predictability sentences were identical and the peripheral hearing for all subjects was within normal limits, the discrepancy in performance would appear to be associated with increasing central auditory processing errors. This test may therefore be sensitive to subtle manifestations of central auditory processing disparities and may indeed reflect on the property of inhibition. This test should command the attention of investigators evaluating pathalogic groups were central auditory processing is suspect, such as learning disabled children, the aging population, dysphasics, and individuals with suspected retrocochlear lesions.

\section{Implications for Future Research}

The results of this study suggest a number of areas for future research. An investigation of the ability of normal hearing older adults to perceive speech in a background of semantically loaded noise may demonstrate additional diagnostic potential of the SPIN test. Research suggests that individuals in older age groups 
require a more adventageous signal-to-noise ratio for understanding speech than is necessary for young adults, perhaps due to difficulties in the central processor (Plomp and Mimpen, 1979). Any deviation in performance from that of young normal hearing listeners, especially on the LP sentences, may reflect deterioration of the auditory pathway or central auditory processing mechanism. Many older hearing impaired listeners obtain a great deal less benefit from the use of hearing aids than do younger adults with equivalent degrees of hearing loss. This discrepancy between potential and actual benefit is frequently attributed to the aging of the central auditory system (Hayes and Jerger, 1979). By routinely administering a shortened version of the SPIN test in noise as part of the hearing aid evaluation, the audiologist may be able to determine quickly and efficiently the amount of central processing disorder experienced by the older listener and its practical effect on hearing aid usage once normative data are obtained on this population. Examination of the SPIN test, especially the LP sentences, as a tool to assist in the selection of appropriate amplification for centrally intact adults is also suggested.

The ability of children to perceive speech in a background of competing noise may also yield important data. Studies by Schwartz and Goldman (1974), Larson and Petersen (1978) and Smyth (1979) suggest that the ambient noise found in many open classrooms imposes a heavy load on children's auditory systems. An investigation of the performance on this speech-in-noise task by normal young 
learners would help the educator to realistically determine individual listening abilities in noisy classroom environments and to compensate for this individual ability when necessary.

The results of this research suggest that this speech-innoise testing procedure would find great application in the learning disabled population. Recent data indicate that speech discrimination ability deteriorates significantly in the presence of noise for some young learners classified as 'learning disabled' (Willeford and Billger, 1978). By including the SPIN procedure in the diagnostic test battery administered to LD children, the audiologist may gain diagnostic insight into the nature and extent of the Individual child's learning disability and into the child's ability to perform as a listener in a group setting. This assessment tool may also provide prescriptive information on a treatment-by-treatment basis for the auditorily disabled learner. Finally, the SPIN test needs further examination regarding the number of sentences contained in each form. Very young and geriatric listeners, as well as those with suspected central auditory processing deficiencies, may not be able to successfully attend to these fifty-word forms, especially if the presentation of several forms is required. Additional investigation of the forms may produce an abbreviated testing tool which will apply more appropriately to these difficult-to-test populations. 
REFERENCES

American National Standards Institute, Specifications for Audiometers. ANSI S3.6-1969, New York: American National Standards Institute, Inc., 1970.

Carhart, R. and Tillman, T.W., "Interaction of Competing Speech Signals with Hearing Losses." Arch. Otolaryn., 91:273-79, 1970 .

Cooper, J.C. and Cutts, B.P., "Speech Discrimination in Noise." JSHR, $14: 332-37,1971$.

Dirks, D.D. and Bower, D.R., "Masking Effects of Speech Competing Messages." JSHR, 12:229-45, 1969.

Doyle, K.J. and Rupp, R.R., "Validation Norms for Speech Discrimination Scores of Normal-Hearing Subjects in Wide-Band and SpeechSpectrum Nolse at S/N 0 dB." JAR, 17:269-73, 1977.

Duffy, J.R. and Giolas, T.G., "Sentence Intelligibility as a Function of Key Word Selection." JSHR, 17:631-37, 1974.

Egan, J.R., "Articulation Testing Methods." Laryngoscope, 58:955-91, 1948 .

Falconer, G.A., "The Reliability and Validity of Monitored Connected Discourse as a Test of the Threshold of Intelligibility." JSHD, $13: 369-71,1948$.

Harris, J.D., "Combinations of Distortions in Speech." Arch. Otolaryn., 72:227-32, 1960 .

Hawkins, J.E. and Stevens, S.S., "The Masking of Pure Tones and of Speech by White Noise." JASA, 22:6-13, 1950.

Hayes, D. and Jerger, J., "Aging and the Use of Hearing Aids." Scand. Audiol., 8:33-40, 1979 .

Hirsh, I.J., The Measurement of Hearing. New York: McGraw-Hil1, 1952.

Hirsh, I.J., Davis, H., Silverman, S.R., Reynolds, E.G., Eldert, E., and Benson, R.W., "Development of Materials for Speech Audiometry." JSHD, 17:321-37, 1952. 
House, A.S., Williams, C.E., Hecker, M.H.L., and Kryter, K.D., "Articulation Testing Methods: Consonantal Differentiation with a Closed-Response Set." JASA, 37:158-66, 1965.

Hull, C.H. and Nie, N.H., SPSS Update - Releases 7 and 8. New York: McGraw-Hil1, 1979.

Jerger, J. and Jerger, S., "Auditory Findings in Brain Stem Disorders." Arch. Otolaryn., 99:342-50, 1974.

Jerger, J., Speaks, C. and Tramme11, J.L., "A New Approach to Speech Audiometry." JSHD, 33:318-28, 1968.

Kalikow, D.N., Stevens, K.N, and Elliott, L.L., "Development of a Test of Speech Intelligibility in Noise Using Sentence Materials with Controlled Word Predictability." JASA, $61: 1337-51,1977$.

Keith, R.W. and Talis, H.P., "The Use of Speech in Noise in Diagnostic Audiometry." JAR, 10:201-4, 1970.

"The Effects of White Noise on PB Scores of Normal and Hearing-Impaired Listeners." Audiology, $11: 177-86,1972$.

Korzybski, A., "A Veteran's Readjustment and Extentional Methods." In Semantics, Thurman, K. (ed.), Boston: Houghton-Miffin, 1960.

Kreul. E.J., Nixon, J.C., Kryter, K.D., Bell, D.W., and Lang, J.S., "A Proposed Clinical Test of Speech Discrimination." JSHR, 11:536-52, 1968.

Kryter, K.D., Williams, C. and Green, D.M., "Auditory Acuity and the Perception of Speech." JASA, 34:1217-23, 1962.

Larson, G. and Petersen, B., "Does Noise Limit the Learning of Young Listeners?" Elem. School J., 78:264-65, 1978.

Lehiste, I. and Peterson, G.E., "Linguistic Considerations in the Study of Speech Intelligibility." JASA, 31:280-86, 1959.

Licklider, J.C.R. and Miller, G.A., "The Perception of Speech." In Handbook of Experimental Psychology, Stevens, S.S. (ed.), New York: John Wiley and Sons, 1951.

Lovrinic, J.H., Burgi, E.J. and Curry, E.T., "A Comparative Evaluation of Five Speech Discrimination Measures." JSHR, 11:372-81, 1968.

Martin, F.N. and Musse11, S.A., "The Influence of Pauses in the Competing Signal on Synthetic Sentence Identification Scores." JSHD, 44:282-92, 1979. 
Miller, G.A., "The Masking of Speech." Psych. Bulletin, 44:105-29, 1947.

Nie, N.H., Hull, C.H., Jenkins, J.G., Steinbrenner, K., and Bent, D.H., Statistical Package for Social Sciences. New York: McGraw-Hill, 1875.

Palva, T., "Studies of Hearing for Pure Tones and Speech in Noise." Acta Otolaryn., 45:231-43, 1955.

Plomp, R. and Mimpen, A.M., "Speech-Reception Threshold for Sentences as a Function of Age and Noise Level." JASA, $66: 1333-42,1979$.

Ross, M., Huntington, D.A., Newby, H.A., and Dixon, R.F., "Speech Discrimination of Hearing-Impaired Individuals in Noise." JAR, 5:47-72, 1965 .

Rupp, R.R. and Phillips, D., "The Effect of Noise Background on Speech Discrimination Function in Normal-Hearing Individuals." JAR, 9:60-63, 1969 .

Schwartz, A.H. and Goldman, R., "Variables Influencing Performance on Speech-Sound Discrimination." JSHR, 17:25-32, 1974.

Silverman, S.R., "The Use of Speech Tests for Evaluation of Clinical Procedures." Trans. Am. Oto1. Soc., July-August, 1950.

Simonton, K.M. and Hedgecock, L.D., "A Laboratory Assessment of Hearing Acuity for Voice Signals Against a Background of Noise." Ann. Otol. Rhino. and Laryngol., 62:735-47, 1953.

Smyth, V., "Speech Reception in the Presence of Classroom Noise." Lng. Sp. and Hrng. in Schools, 10:2.21-3n, 1979.

Speaks, C. and Jerger, J., "Method for Measurement of Speech Identification." JSHR, 8:185-94, 1965.

Thornton, A.R. and Raffin, M.J.M., "Speech Discrimination Scores Modeled as a Binomial Variable." JSHR, 21:507-18, 1978.

Wilbur, L., "Calibration, Pure Tone, Speech and Noise Signals." In Handbook of Clinical Audiology, Katz, J. (ed.), Baltimore: Williams and Wilkins, 1978.

Willeford, J.A. and Billger, J.M., "Auditory Perception in Children with Learning Disabilities." In Handbook of Clinical Audiology, Katz, J. (ed.), Baltimore: Williams and Wilkins, 1978.

Winer, B.J., Statistic Principles in Experimental Designs. New York: McGraw-H111, 1963. 